\title{
Study of longitudinal heat transfer in low temperature heat pipes with axial grooves and discrete metal fibres for space thermal control systems
}

\author{
V. Baturkin \& T.-M. Ho \\ Institute of Space Systems, German Aerospace Center, Bremen, Germany
}

\begin{abstract}
Heat pipe technology became an integral part of the thermal control systems of space missions to transfer heat and control the temperature. The selection, design and the integration of heat pipes in space hardware requires the knowledge about their thermal performance. One of the major characteristics is the longitudinal resistance. This paper presents the experimental results of the longitudinal heat transfer in constant and variable thermal resistance heat pipes (HP) with diameters between 0.006 to $0.012 \mathrm{~m}$ : "a") aluminium - ammonia HP with axial grooved capillary structure; "b") stainless steel - methanol HP with stainless steel discrete metal fibre capillary structure; "c") copper - methanol HP with copper discrete metal fibre capillary structure. The tests have been performed within a wide range of operation parameters: heat sink temperature from -75 up to $+60^{\circ} \mathrm{C}$, the transferred heat power from 0.5 up to $100 \mathrm{~W}$, the axial heat flux density up to $250 \mathrm{~W} / \mathrm{cm}^{2}$. As characteristic parameter the longitudinal thermal resistance $\mathrm{R}_{\mathrm{HP}}=\left(\mathrm{T}_{\mathrm{ev}}-\mathrm{T}_{\text {con }}\right) / \mathrm{Q}_{\mathrm{HP}}$ is used, where $\mathrm{Q}_{\mathrm{HP}}$ is the transferred heat power and $\mathrm{T}_{\mathrm{ev}}$ and $\mathrm{T}_{\text {con }}$ are the average temperatures of the heat input and output zones, respectively. For the HPs " $a$ " the parameter $\mathrm{R}_{\mathrm{HP}}$ varies from 0.06 to $0.045 \mathrm{~K} / \mathrm{W}$. The change of $\mathrm{T}_{\text {con }}$ has no essential impact on the HP thermal resistance. For the HP "b", $\mathrm{R}_{\mathrm{HP}}$ changes from 80 to $4 \mathrm{~K} / \mathrm{W}$. The physical basis of such behaviour is related to the formation of vapor and non-condensable gas boundary in the coldest part of the heat pipe and, as consequence, a heat transfer intensity variation. The HPs "c" have shown essential impact of $\mathrm{T}_{\text {con }}$ on resistance, which varies from 70 to $0.4 \mathrm{~K} / \mathrm{W}$. The physical basis of such behaviour is connected a change of the vapor flow regime in the inner vapor space and with change of the inner heat transfer
\end{abstract}


intensity. The comparison of the longitudinal heat transfer characteristics of different types of heat pipes allows us to define their functional abilities in thermal control systems (TCS) for different space applications and to use these data in TCS mathematic models.

Keywords: thermal control, heat pipe, heat transfer, study.

\section{Introduction}

The development of space thermal control technique is tightly connected with the achievements of heat pipe science and technology during the last 45 years [1-6]. As the main elements of TCS the different types of heat pipes are used: conventional heat pipes (HP), variable conductance (or resistance) heat pipes (VCHP), thermal diodes (TD), characteristics of which are described in Figure 1.

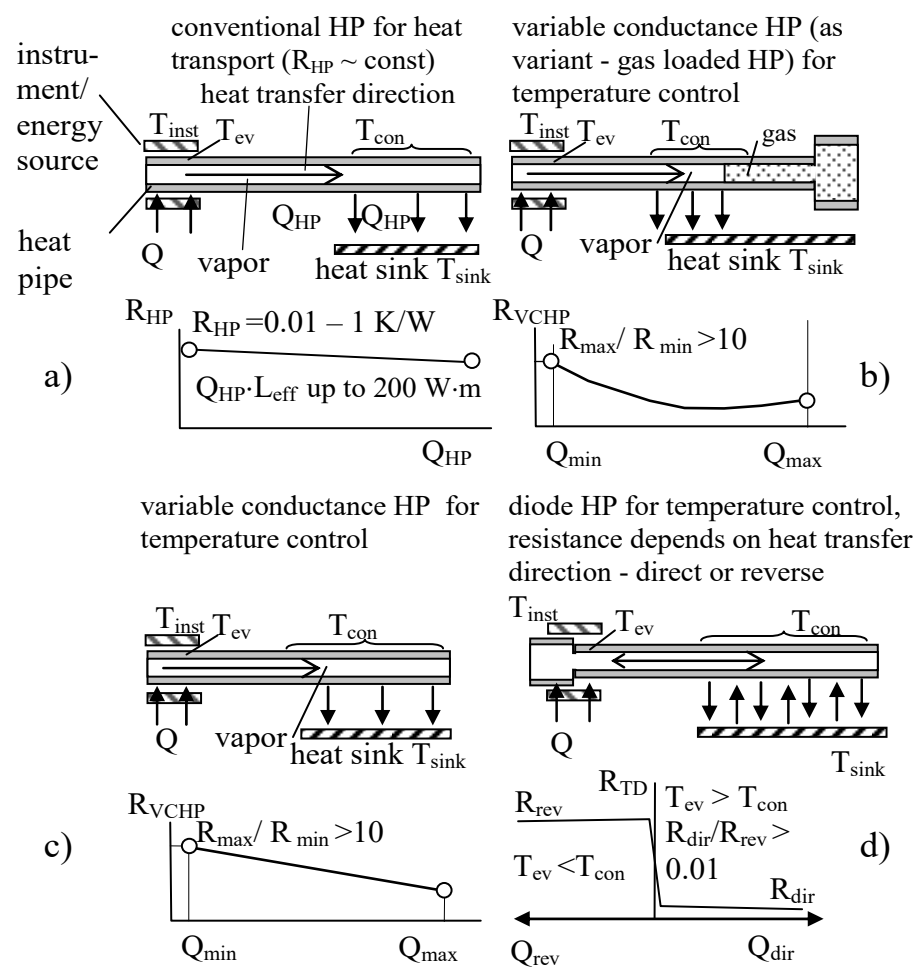

Figure 1: Scheme of various heat pipe types and dependence of the thermal resistance on the transferred heat power QнР; a) - constant conductance HP; b), c) - variable conductance HPs; d) - thermal diode (switch). $\mathrm{T}_{\text {inst }}, \mathrm{T}_{\text {sink }}-$ temperature of instrument and heat sink.

HPs could be characterized by function of longitudinal thermal resistance $R_{H P}$ $[\mathrm{K} / \mathrm{W}]=\left(\mathrm{T}_{\mathrm{ev}}-\mathrm{T}_{\text {con }}\right) / \mathrm{Q}_{\mathrm{HP}}=\mathrm{f}\left(\mathrm{Q}_{\mathrm{HP}}, \mathrm{T}_{\mathrm{con}}\right)$, where $\mathrm{Q}_{\mathrm{HP}}$ is the power transferred from heat input zone (evaporator) to the heat output zone (condenser). 
Heat transfer in HPs of different types. Typical representative of conventional heat pipe are heat pipes with ammonia and grooved capillary structure due to the following advantages: an ability to transfer the heat on length 1-4 m (more $\left.200 \mathrm{~W}^{*} \mathrm{~m}\right)$ and low thermal resistance $(0.1 \mathrm{~K} / \mathrm{W}$ and lower $)$ that is important for space applications. Each geometry of grooves (rectangular, trapezoid and $\Omega$ shape) have specific intrinsic heat exchange characteristics. The explanation of heat transfer mechanism in heat input zone and condenser in 1960-70 yy. was based on the definition of heat conductivity in liquid channels and metal rib between grooves [4]. Later the profile of thin liquid film at the groove edge was defined, opened to vapor channel. Estimations concluded that microfilm zone of liquid meniscus in the heated zone has a length of only a few microns, but up to $40 \%$ energy is passed to the vapor through it [7-10]. Heat transfer intensity in condenser is based on the definition of liquid layer profile and its thickness inside grooves and on the top of the metal rib. Due to variety of operational regimes and not fully understandable heat transfer mechanisms, there is a wide deviation of intensity values compared with proposed simulation models [11]. Therefore, experimental study of heat transfer in such HP type is still actual.

Variable conductance (resistance) heat pipes regulate their thermal resistance passively. The most usable type of VCHP is gas loaded heat pipe (GLHP) with non-condensable gas (NCG). NCG essentially reduces the intensity of the vapor condensation in a certain part of the GLHP. The mechanism of temperature regulation and heat exchange in gas -vapor zone is fundamentally investigated in early works $[1-5,12,13]$. Currently GLHP study is connected with simplification of design, increasing of the ratio of resistance change, expansion of the area of application in terms of power and heat sink temperature variation.

Another type of VCHP uses the heat transfer intensity variation inside the heat pipe which is the function of vapor saturation temperature $T_{v}$ or condenser temperature $\mathrm{T}_{\text {con }}$, and the heat flux density in heat input and output zones. The change of the resistance $\mathrm{R}_{\mathrm{VCHP}}$ could reach more than one order of magnitude. This heat pipe type is new in space application. The physical reason for the large resistance change is one or several physical limitations of HP operation [4], which usually are eliminated in convection heat pipes. Among them are the limitation of vapor sound velocity, crisis in heat carrier circulation and so on.

Thermal diodes (TD) have low resistance at the direct heat transfer $R_{\text {dir }}\left(T_{e v}>\right.$ $\mathrm{T}_{\text {con }}$ ) and very large one, if $\mathrm{T}_{\mathrm{ev}}<\mathrm{T}_{\text {con }}$ (reverse regime, $\mathrm{R}_{\mathrm{rev}}$ ). The ratio $\mathrm{R}_{\mathrm{rev}} / \mathrm{R}_{\mathrm{dir}}$ reaches two orders of magnitude.

All heat pipe types are intended for temperature control, actively participating in the formation of the corresponding instrument heat balance. Traditional radiative TCS with heat pipe looks as the following (see Figure 2a): the instrument, having temperature $T_{\text {inst }}$ with a power generation $Q$ is thermally connected with a radiator through a thermal resistance $\mathrm{R}_{\mathrm{HP}}$, that is the sum of the resistances in the evaporator $R_{\mathrm{ev}}$ and the condenser $R_{\text {con }}$ (for example calculation $R_{H P}=0.2 \mathrm{~W} / \mathrm{K}$, $\mathrm{Q}=2 \ldots 10 \mathrm{~W}$ ). The radiator (with temperature $\mathrm{T}_{\mathrm{rad}}$ and illuminated and heat absorbing areas are $\mathrm{F}_{\mathrm{rad}}$ ) absorbs from space the heat flux with a density $\mathrm{q}_{\mathrm{ex}}$ (sun light, IR radiation of the Earth, reflection of external elements). The task of the TCS is to provide the instrument temperature $\mathrm{T}_{\text {inst }}$ inside of the operation 
temperature range, as an example for electronics, $\mathrm{T}_{\text {inst, } \min }=-40^{\circ} \mathrm{C}$ and $\mathrm{T}_{\text {inst,max }}=+65^{\circ} \mathrm{C}$ with varying instrument power generation (in example from 2 to $10 \mathrm{~W}$ ) and external illumination of radiator. In scheme "a" the temperatures of the instrument and radiator are very close to each other (Note: difference between them equals $\mathrm{R}_{\mathrm{HP}} \cdot \mathrm{Q} \sim 2^{\circ} \mathrm{C}$ ); at lower power generation $\mathrm{Q}=2 \mathrm{~W}$ and lower external fluxes $\mathrm{q}_{\mathrm{ex}}<100 \mathrm{~W} / \mathrm{m}^{2}$ there is a chance to overcool the instrument. Traditional active means to avoid overcooling is to add the subsidiary heat to the radiator or to the instrument.

A temperature stabilization, realized of scheme "b" is reached by a passive change of active condensation area in the condenser and radiative area on the radiator, varying $R_{V C H P}$ and $R_{\text {rad. }}$ The instrument temperature lies inside of the temperature operation limits at $R_{H P, \max } / R_{H P, \text { min }}>3$. Higher value of $R_{\max }$ and larger value $R_{\max } / R_{\min }$ narrow the variation of the instrument temperature.

New approach of temperature regulation foresees to change the total resistance $\mathrm{R}_{\mathrm{HP}}$ (scheme "c"). In the simulation if to assume $\mathrm{R}_{H P}=\mathrm{R}_{\max }\left[1-\left(\mathrm{T}_{\mathrm{rad}}\right.\right.$ -

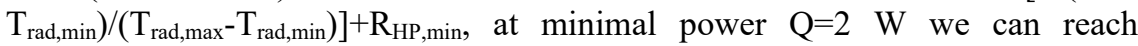
stabilization of the instrument temperature $T_{\text {inst }}>T_{\text {inst, min }}$ at a ratio $R_{\max } / R_{\min }>80$.

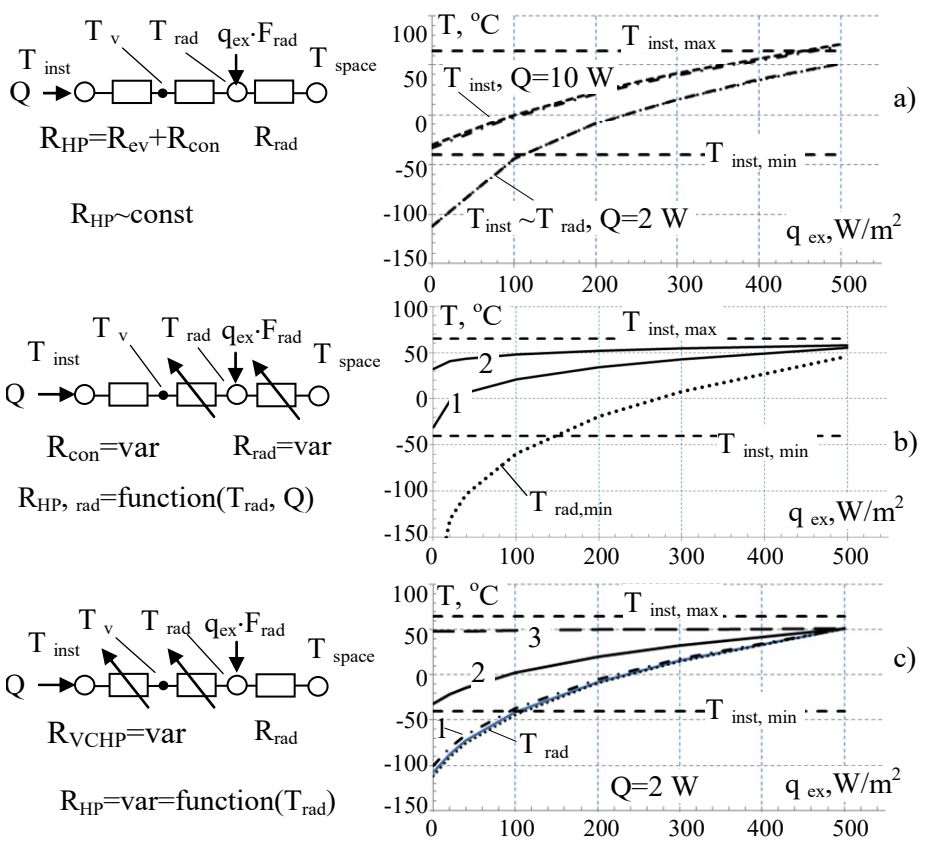

Figure 2: Simplified scheme of TCS with the heat pipes: a) - scheme with constant resistance of heat pipe; $b, c-$ with variable resistance of heat pipes. On b): $1,2-\mathrm{T}_{\text {inst }}$ at $\mathrm{Q}=2 \mathrm{~W}$ and $\mathrm{R}_{\max } / \mathrm{R}_{\min }=20$ and different $\mathrm{R}_{\max }=90$ and $120 \mathrm{~K} / \mathrm{W}$, respectively. On c): $1,2,3-\mathrm{T}_{\text {inst }}$ at $\mathrm{HP}$ resistance change $R_{\max } / R_{\min }=10 ; 80 ; 160$, respectively at $\mathrm{Q}=2 \mathrm{~W}$. $\mathrm{T}_{\mathrm{v}}$ - vapor temperature. 
For every considered HP type it is important to know their longitudinal resistance functionalities. Literature sources contain not sufficient and in some cases contradictory information on the operation of such types of heat pipes in the wide range of exploitation temperatures and powers. Therefore, in the Institute of space systems of German Aerospace Center (DLR, Bremen, Germany) in the frame of the project Mascot [14] (design of "miniature lander for asteroid studies") the comparative study of longitudinal heat transfer in three types of heat pipes that are perspective for the project implementation has been undertaken.

\section{Objects for study}

Three heat pipe types were studied with the following parameters, see Table 1 . The shell external diameter, zones' length, and shell materials fit good with the assembly requirements for actual space projects, and the expected thermal performance - could be sufficient for the development of different TCS.

Table 1: Description of heat pipes used for investigations.

\begin{tabular}{|c|c|c|c|}
\hline & $\begin{array}{c}\text { "a" aluminium } \\
\text { - ammonia } \\
\text { HPs }\end{array}$ & $\begin{array}{c}\text { "b" stainless steel - } \\
\text { methanol HPs }\end{array}$ & $\begin{array}{l}\text { "c" copper - } \\
\text { methanol HPs }\end{array}$ \\
\hline $\mathrm{L}_{\mathrm{HP}}, \mathrm{m}$ & 0.952 & 0.55 & 0.482 and 0.428 \\
\hline $\mathrm{L}_{\mathrm{eV}} / \mathrm{L}_{\mathrm{HP}}$ & 0.334 & 0.37 & 0.199 and 0.23 \\
\hline $\mathrm{L}_{\text {con }} / \mathrm{L}_{\mathrm{HP}}$ & 0.299 & 0.37 & 0.26 and 0.22 \\
\hline $\mathrm{L}_{\mathrm{ad}} / \mathrm{L}_{\mathrm{HP}}$ & 0.36 & 0.27 & 0.54 and 0.57 \\
\hline Mass, kg & 0.22 & 0.6 (with radiator) & 0.129 and 0.11 \\
\hline $\begin{array}{l}\text { Shell external } \\
\text { diameter, } \mathrm{m}\end{array}$ & 0.0122 & 0.01 & 0.006 \\
\hline Configuration & $\begin{array}{l}\text { U-shape, two } \\
\text { bending } 90 \\
\text { grad r }=48 \mathrm{~mm} \\
\end{array}$ & $\begin{array}{l}\text { U-shape, one bend } \\
180 \operatorname{grad~} \mathrm{r}=50 \mathrm{~mm}\end{array}$ & $\begin{array}{l}4 \text { and } 5 \text { bending } \\
45 \ldots 135 \text { grad } \\
r=16 \mathrm{~mm}\end{array}$ \\
\hline $\begin{array}{l}\text { Capillary } \\
\text { structure }\end{array}$ & $\begin{array}{l}\text { axial grooved } \\
0.5 \times 1 \mathrm{~mm}, \\
30 \text { units }\end{array}$ & $\begin{array}{l}\text { stainless steel } \\
\text { discrete metal fibre, } \\
\text { fibre diameter } 30 \\
\mu \mathrm{m} \text {, length } 3 \mathrm{~mm}, 1 \\
\text { mm thick }\end{array}$ & $\begin{array}{l}\text { copper discrete } \\
\text { metal fibre, fibre } \\
\text { diameter } 70 \mu \mathrm{m} \text {, } \\
\text { length } 7 \mathrm{~mm} \text {, } \\
1 \mathrm{~mm} \text { thick }\end{array}$ \\
\hline Type & $\begin{array}{l}\text { constant } \\
\text { thermal } \\
\text { resistance }\end{array}$ & $\begin{array}{l}\text { variable resistance } \\
\text { with non- } \\
\text { condensable gas }\end{array}$ & $\begin{array}{l}\text { variable resistance } \\
\text { with inner heat } \\
\text { transfer changing }\end{array}$ \\
\hline
\end{tabular}

The heat pipes were designed and fabricated by the National Technical University of Ukraine "Kyiv Polytechnic institute" (Kyiv, Ukraine) subcontracted by DLR [15-17].

Thermal studies of the heat pipes were conducted in vacuum in the horizontal position of the HP's longitudinal axis or the bending plane. A typical experimental bench is shown in Figure 3. 


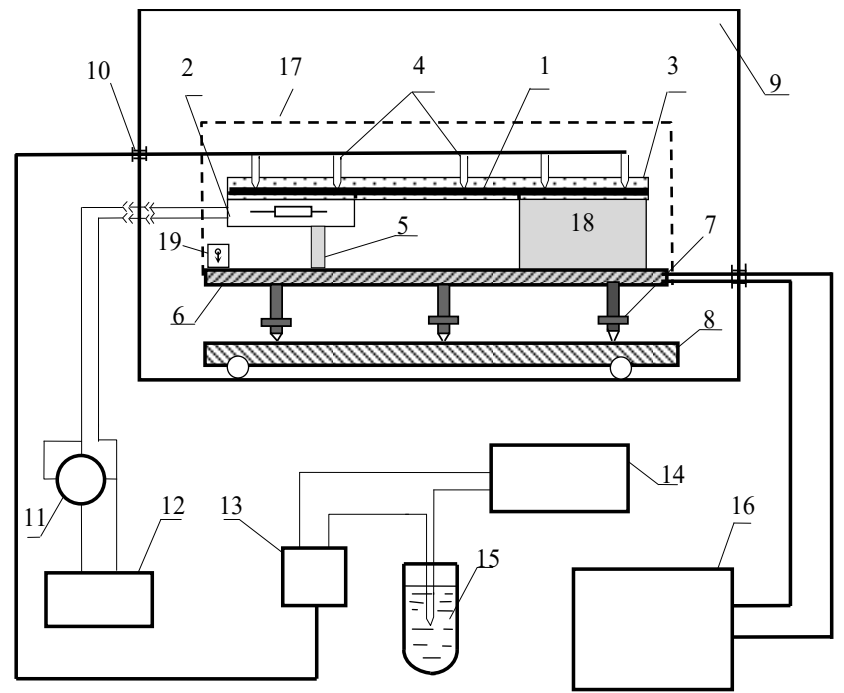

Figure 3: Scheme of experimental bench for the heat pipe longitudinal conductivity study. 1 - heat pipe to be tested; 2 - heater; 3 - insulation; 4 - temperature sensors (thermocouples or thermal resistors); 5 - distance-piece; 6 - mounting plate with regulated temperature; 7 - supports for regulation of tilt; 8 - base plate; 9 - vacuum chamber; 10 - hermetic connector for thermocouples; 11 - power meter; 12 - source of regulated and stabilised voltage; 13, 14 - measurement system; $15-0^{\circ} \mathrm{C}$ thermostat (only for thermocouple); 16 - liquid circulation thermostat; 17 - thermal shield; 18 - heat sink; 19 - levelling.

The heat pipe (1), coated with thermal insulation with pre-installed heater (2) and temperature sensors (4) is placed on a mounting plate (6) with regulated temperature via distance-pieces (5) and heat sink (18). The required inclination of the HP longitudinal axis is regulated by 3 supports (7), using the indicator of levelling (19). To minimize the thermal impact of the external temperature, the assembly is closed by thermal shield (17), having the same temperature as the mounting plate (6). The electrical heater is powered from the source of the regulated and stabilised voltage (12) and measured by a powermeter (11) or a combination of an ampere-meter and voltmeter.

The testing procedure includes temperature stabilization at zero applied power at selected temperature levels (inside the range $-75 \ldots+60^{\circ} \mathrm{C}$ ). Then a certain electrical power is applied to the heater and kept constantly until steady-state temperature is reached. The criteria of steady state regime is defined as a variation of the vapor and shell temperatures in evaporation zone of less than $0.2 \mathrm{~K} /$ hour. The applied electrical power and temperature profile are recorded.

Processing of initial test data for steady state regimes includes the estimation of heat exchange of tested object with the surroundings via thermal insulation, wires, supports, and the definition of the longitudinal thermal resistance $\mathrm{R}_{\mathrm{HP}}$ 


$$
R_{H P}=\left(T_{e v}-T_{c o n}\right) / Q_{H P},
$$

where $\mathrm{T}_{\mathrm{ev}}$ and $\mathrm{T}_{\mathrm{con}}$ are averaged per length (for HP "a, c") and extreme (for HP " $b$ ") temperature in the heat input and output zones, $\mathrm{Q}$ is the transferred power.

The tests for heat pipes " $a, b$, c" were conducted on the facilities of the NTUU "KPI" (Ukraine), for "a, c" and in DLR (Berlin/Bremen, Germany).

\section{Obtained results}

\subsection{Constant conductance heat pipes}

This type of heat pipes has an extruded aluminium shell with inner axial rectangular-shape grooves and is widely used in space thermal control. Unambiguous information on the longitudinal thermal resistance variation as a function of $\mathrm{T}_{\text {con }}$ and $\mathrm{Q}_{\mathrm{HP}}$ can be found in literature. 25 similar heat pipes were fabricated and tested in the course of the microsatellite BIRD (DLR) thermal control system development and qualification. The summarized functions $R_{H P}$ for protoflight HP group are presented in Figure 4. Experimental data were obtained at the condition $\mathrm{T}_{\text {con }}=$ const, independently on the value of heat $\mathrm{Q}_{\mathrm{HP}}$.
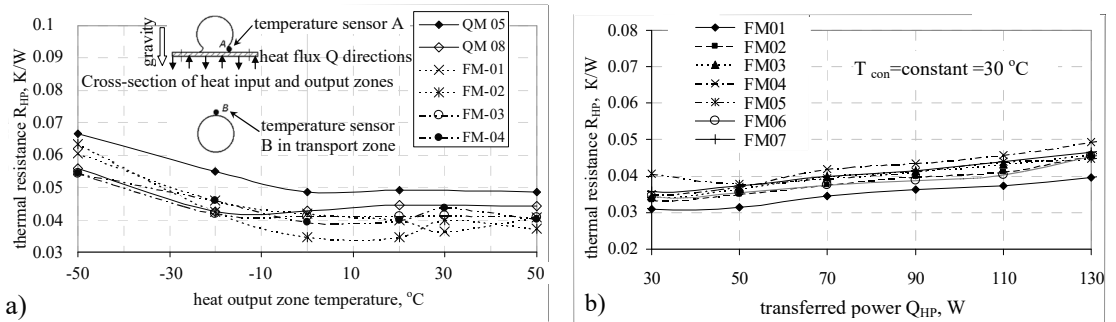

Figure 4: Thermal resistance $\mathrm{R}_{\mathrm{HP}}$ as the function of heat output zone temperature $\mathrm{T}_{\text {con }}$ at transferred power $90 \mathrm{~W}$ (a) and as function of transferred heat power at $\mathrm{T}_{\text {con }}=+30^{\circ} \mathrm{C}(\mathrm{b}) . \mathrm{QM}, \mathrm{FM}-$ abbreviation of heat pipes. The sensors' data in locations " $\mathrm{A}$ " and " $\mathrm{B}$ " were used for $\mathrm{R}_{\mathrm{HP}}$ definition.

A reduction of the thermal resistance $R_{H P}$ is observed with $T_{\text {con }}$ rising. This affect is mainly connected with an increase of the heat exchange intensity in the heat input zone. The thermal resistance is generalized by the approximation

$$
R_{H P}=2.84 \cdot 10^{-6} \cdot T_{\text {con }}{ }^{2}-0.00017 \cdot T_{\text {con }}+0.042 \quad[\mathrm{~K} / \mathrm{W}]
$$

with a deviation $\pm 0.0075 \mathrm{~K} / \mathrm{W}, \mathrm{T}_{\text {con }}-$ in $\operatorname{grad} \mathrm{C}$.

The experimental values of the heat transfer intensity in the heat input zone (pertaining to area $\pi \cdot \mathrm{L}_{\mathrm{ev}} \cdot \mathrm{d}_{\mathrm{v}}$, index $\mathrm{v}$ is vapor) for this type of rectangular grooves change in the range $(5000 \ldots 10000) \pm 20 \% \mathrm{~W} /\left(\mathrm{m}^{2} \mathrm{~K}\right)$ inside a temperature diapason from -50 to $+50^{\circ} \mathrm{C}$ with a local heat flux density up to $6 \mathrm{~W} / \mathrm{cm}$. Experimental values of heat transfer intensity in heat output zone (pertaining to area $\pi \cdot \mathrm{L}_{\mathrm{con}} \cdot \mathrm{d}_{\mathrm{v}}$ ) for this type of rectangular grooves change in the range of 4500 to $5500 \pm 20 \%$ 
$\mathrm{W} /\left(\mathrm{m}^{2} \mathrm{~K}\right)$. The $\mathrm{R}_{\mathrm{HP}}$ variation is not sufficient to narrow the instrument temperature variance at the condition of $\mathrm{T}_{\text {con }}$ and $\mathrm{Q}_{\text {inst }}$ change.

\subsection{Variable conductance heat pipe with non-condensable gas}

This heat pipe type is characterised by the creation of a movable boundary between the vapor and the non-condensable gas, which is added into the inner vapor space during the fabrication. NCG quantity defines the heat input zone stabilization temperature. The increase in power moves the "vapor-gas" boundary deeper inside the condenser, thus opening for active condensation a new area of condenser (see Figure 5a).
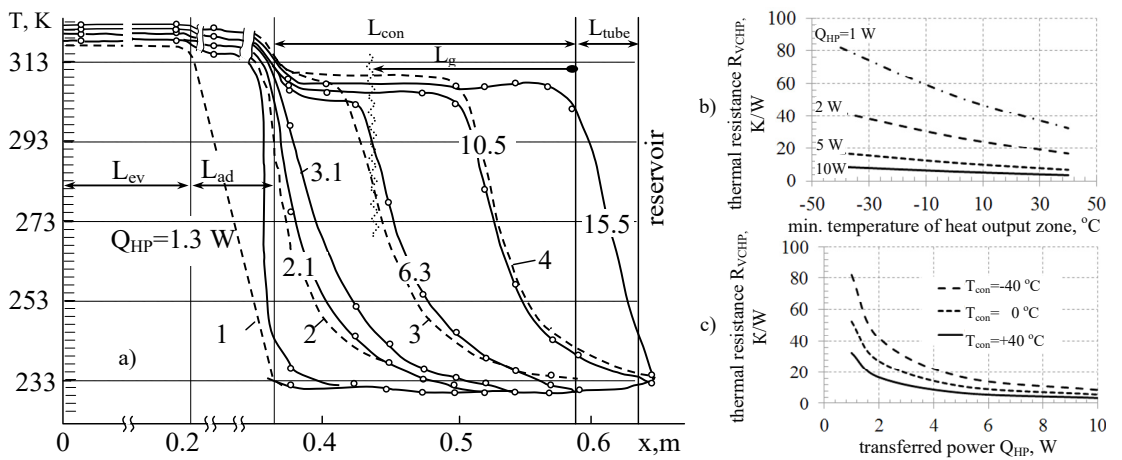

Figure 5: Operation of variable conductance heat pipe; a - temperature profile along HP length; On a) - curves 1-4 (analytical prediction with 1D conductive model); $\mathrm{L}_{\mathrm{g}}$ - assumed location of "vapor-gas" boundary at power $6.3 \mathrm{~W}$. Experimental values of thermal resistance as a function of heat output zone temperature b) and transferred power c).

The inner heat exchange in evaporator is characterised by the intensity $450 \ldots 500 \mathrm{~W} /\left(\mathrm{m}^{2} \mathrm{~K}\right)$, pertaining to area $\pi \cdot \mathrm{L}_{\mathrm{ev}} \cdot \mathrm{d}_{\mathrm{v}}$. Shell temperature dispersion in the heat input zone is less than $0.5^{\circ} \mathrm{C}$ on a length of $0.2 \mathrm{~m}$.

\subsection{Variable conductance heat pipes with changing inner heat transfer}

This type of heat pipe is intended for the regulation of instrument temperature by the essential change of the heat transfer intensity in the heat input and output zones and in the vapor space. The physical reasons of this change are classified as the following: the influence of the saturation pressure on heat transfer, observed in $[18,19]$, the interruption of the nominal "liquid - vapor" circulation inside the heat pipe due to hydrodynamic limitation, the vapor flow and sonic velocity limitation [4, 20-22], interaction "vapor-liquid" flow limits [22], transformation from free molecular to continues vapor flow [21]. For methanol as heat carrier, the classic thermophysical parameters, defining the HP operation criteria change very widely within temperature range $-80 \ldots+70^{\circ} \mathrm{C}$ (Figure 6a, b).

At temperature less than $-60^{\circ} \mathrm{C} \mathrm{HP}$ has the limitation at sonic velocity (point 1 ), less than $-40^{\circ} \mathrm{C}$ the free vapor molecular takes the place with number $\mathrm{Kn}>0.01$ 
(point 2), that produce high temperature drops in vapor [21], in range $-40 \ldots-20^{\circ} \mathrm{C}$ liquid transport factor $\mathrm{N}_{1}$ makes $35 \%$ of this value at $+60^{\circ} \mathrm{C}$. These effects bring to highest value of longitudinal resistance of at $\mathrm{T}_{\text {con }}=-75 \ldots-20^{\circ} \mathrm{C}$.

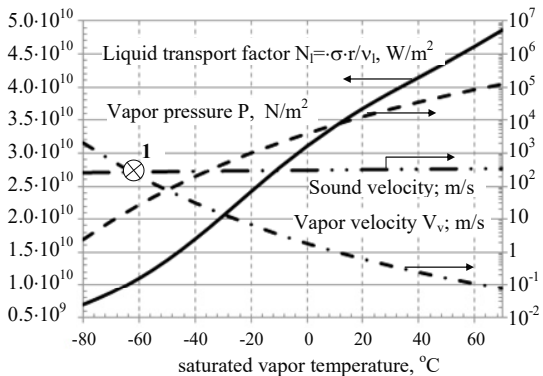

a)

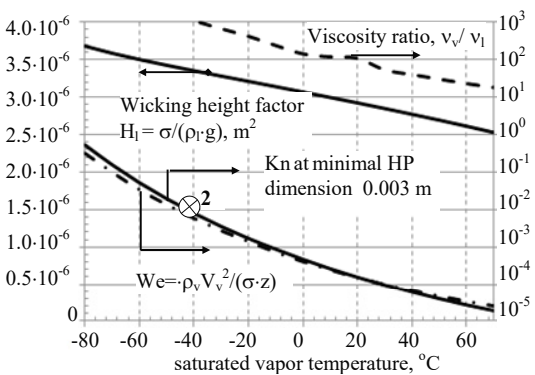

b)

Figure 6: Characterization criteria of methanol as heat carrier for heat pipe; a) liquid transport factor $\mathrm{N}_{\mathrm{l}}$, vapor saturation pressure $\mathrm{P}$, sonic velocity; theoretical vapor velocity $\mathrm{V}_{\mathrm{v}}$ at power $1 \mathrm{~W}$ and vapor channel diameter $0.003 \mathrm{~m}$; b) - Weber number We (characteristic size $\mathrm{z}=50 \mu \mathrm{m})$, wicking height factor $\mathrm{H}_{\mathrm{l}}$, kinematic viscosity ratio $v_{\mathrm{v}} / v_{\mathrm{l}}$, Knudsen number Kn; $\sigma, r, v, \rho$ - surface tension, heat of evaporation, kinematic viscosity, density, index 1 - liquid, index $\mathrm{v}$ - vapor.

Experimental investigations of such type of heat pipes were linked to the development of the Mascot lander TCS $[14,17]$ and therefore include different geometries: 1D (the straight-line), 2D (bending in one plane in similar manner as the Flight HP) and the 3D Qualification and Flight configuration (Figure 7). 1D geometry tests confirmed the principle of the temperature regulation; the 2D tests have demonstrated their transport ability in the condition of the minimal effect of Earth gravity; the 3D test showed the HP performance under the gravity condition in the reflux mode, in the orientation, similar to the thermal vacuum test with the whole TCS (gravity assisted).

The typical HP performance characteristics are featured by the following dependences - at the lowest heat sink temperatures $\left(-76 \ldots-40^{\circ} \mathrm{C}\right)$ and the lowest heat input powers $(0.4 \ldots 1.5 \mathrm{~W})$ the thermal resistance reaches $10 \ldots 70 \mathrm{~K} / \mathrm{W}$, similar to the resistance of the metallic copper tube. At the highest heat sink temperatures $\left(+20 \ldots+60^{\circ} \mathrm{C}\right)$ and powers $(2 \ldots 15 \mathrm{~W})$ thermal resistance shifts to values $0.4 \ldots 0.6 \mathrm{~K} / \mathrm{W}$, similar to the conventional HP, Figure $8 \mathrm{a}), \mathrm{b}$ ).

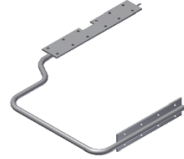

2D

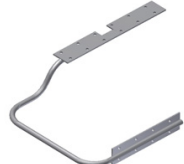

$3 \mathrm{D}$

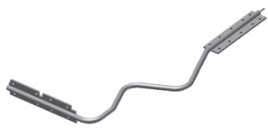

2D

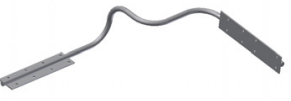

$3 \mathrm{D}$

Type A

Figure 7: Configuration of $2 \mathrm{D}$ and $3 \mathrm{D}$ heat pipes of two types $\mathrm{A}$ and $\mathrm{B}$. 

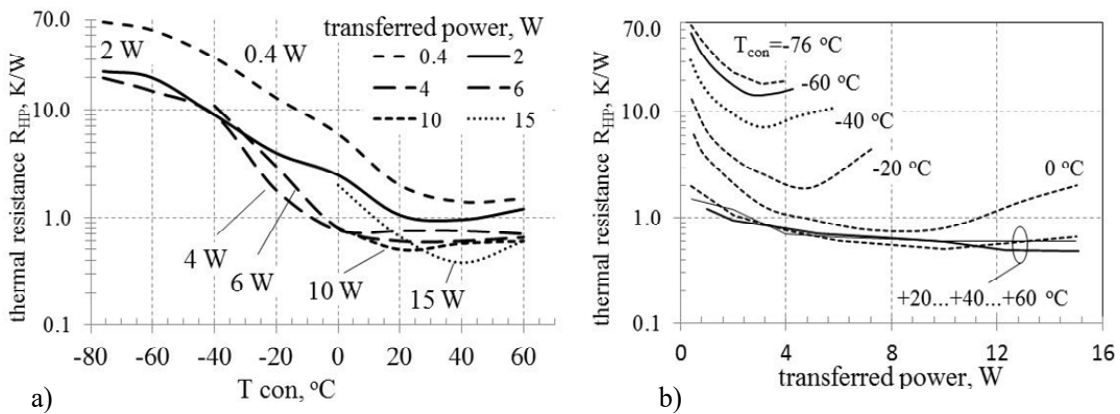

Figure 8: Thermal resistance as the function of heat output zone temperature (a) and as function of transferred power (b). Results are for HP with 3D configuration, type B.

The investigations of all HPs' geometries confirmed the variable thermal properties which are the function of the transferred heat power and the condenser temperature. However, deviations in the curves due to gravity and variance in the capillary structure parameters and liquid quantity are observed.

The source of errors for $\mathrm{R}_{\mathrm{HP}}$ definition differ at the regimes with high thermal resistance (value $70 \mathrm{~K} / \mathrm{W}$ ) and low one (level $0.4 \mathrm{~K} / \mathrm{W}$ ). In regime with high resistance the main source of error is linked with the definition of heat leak ( $\left.Q_{\text {leak }}\right)$ via insulation, heaters and sensors wires, supports, sensors heat exchange. This takes place due to largest temperature difference between HP and surrounding. At low HP thermal resistance these leaks become small compared with value $\mathrm{Q}_{\mathrm{HP}}$ and measurement of temperature drop produces the largest error. The maximal relative error of the HP resistance definition $\Delta R_{H P} / R_{H P}$ could be expressed by next formulation [23]:

$$
\frac{\Delta R_{H P}}{R_{H P}}=\frac{\Delta Q_{H P}}{Q_{H P}}+\frac{\Delta T_{e v}+\Delta T_{c o n}}{T_{e v}-T_{c o n}} .
$$

Using (3) the following errors are obtained for maximal relative errors. For the heat pipe mode at $\mathrm{T}_{\text {con }}=-20 \ldots+60^{\circ} \mathrm{C}$ is $\Delta \mathrm{R}_{\mathrm{HP}} / \mathrm{R}_{\mathrm{HP}} \pm 0.17$ (the minimal power) to \pm 0.12 (the maximal power). For the large resistance mode $\left(\mathrm{T}_{\text {con }}=-76 \ldots-40^{\circ} \mathrm{C}\right)$ $\Delta \mathrm{R}_{\mathrm{HP}} / \mathrm{R}_{\mathrm{HP}}$ is from \pm 0.22 to \pm 0.15 .

\section{Conclusions}

Heat pipes with axial rectangular grooves. The obtained functions $\mathrm{R}_{\mathrm{HP}}$ show no essential change with varying temperature level and power transferred, and thus has a little effect on stabilization of the instrument temperature. The absolute value of $\mathrm{R}_{\mathrm{HP}}$ is low enough, about $0.05 \mathrm{~K} / \mathrm{W}$. Therefore, the temperature of the instrument is very close to the radiator or heat sink temperature. The isothermality of the heat input/output zones along the HP length is less than $0.5^{\circ} \mathrm{C}$ per $0.3 \mathrm{~m}$, allowing to use such HP type for the creation of isothermal base for heat generated 
instruments and for uniform heating/cooling. Heat pipes operate similar in both directions of the heat flux and with one - and two sides heat input. These HPs have demonstrated lifetime more than 12 years' operation in space (as the part of TCS of near-Earth microsatellite BIRD, designed by DLR).

Heat pipes with non-condensable gas. This type is useful for narrowing the instrument temperature exploitation range, when it operates in a wide variation of instrument power generation and heat sink temperatures (or absorbed heat fluxes). Sensitivity to variation of power generation is about $\partial \mathrm{T}_{\text {inst }} /\left.\partial \mathrm{Q}_{\text {inst }}\right|_{\mathrm{T} \text { con }=\text { const }}=0.45$ $\mathrm{K} / \mathrm{W}$, and sensitivity to variation of external heat flux or heat sink temperature is about $\partial \mathrm{T}_{\text {inst }} /\left.\partial \mathrm{T}_{\text {con }}\right|_{\text {Qinst }=\text { const }}=0.38 \mathrm{~K} / \mathrm{K}$. Reachable variation of $\mathrm{R}_{\max } / \mathrm{R}_{\min }$ makes $80 \mathrm{~K} / \mathrm{W}: 4 \mathrm{~K} / \mathrm{W}$.

Heat pipes with inner heat transfer changing. This type is useful for narrowing the instrument temperature variation, that operates in a wide variation of power generation and heat sink temperatures (or external heat fluxes). At low power generation $(0.4 \ldots 1 \mathrm{~W})$ and low absorbed external flux $\left(\mathrm{T}_{\mathrm{con}}=-76 \ldots-40^{\circ} \mathrm{C}\right.$, $\left.\mathrm{q}_{\mathrm{ab}}=0 . .80 \mathrm{~W} / \mathrm{m}^{2}\right)$ the longitudinal resistance became highest $(10 \ldots 70 \mathrm{~K} / \mathrm{W})$ and the HP thermally isolate the radiator and instrument. By increasing the heat generation or increasing $\mathrm{q}_{\mathrm{ex}}$ (up to $600 \mathrm{~W} / \mathrm{m}^{2}$ ) the HP reduces its resistance to $0.4 \ldots 0.6 \mathrm{~K} / \mathrm{W}$. The sensitivity to variation of heat sink temperature is about $\partial \mathrm{T}_{\text {inst }} /\left.\partial \mathrm{T}_{\text {con }}\right|_{\mathrm{Qinst}}=2$ and $10 \mathrm{~W}=0.7$ and $0.1 \mathrm{~K} / \mathrm{K}$. Reachable variation of $\mathrm{R}_{\max } / \mathrm{R}_{\min }$ makes $70 \mathrm{~K} / \mathrm{W}: 0.4 \mathrm{~K} / \mathrm{W}$ Theoretical basis allowing to predict HP thermal characteristics should be elaborated in details with respect to possible variation of the HP shell diameters, length of heat input/output zones, quantity/type of heat carrier, and type of capillary structure, possibly to adjust stabilization temperature.

\section{References}

[1] Bienert W., Brennan P., Kirkpatrick J. Feedback controlled variable conductance heat pipes. AIAA Paper, 421, pp. 1-11, 1971.

[2] Marcus B., Theory and design of variable conductance heat pipes, TRW systems Group, Report NASA-CR - 2O18, 248 p., 1972.

[3] Groll M., Hage M. Development of an electrical feedback controlled variable conductance heat pipes for space applications, AIAA Paper, 752, pp. 1-7, 1974.

[4] Brennan P., Kroliczek E., Heat Pipe Design Handbook, B \& K Engineering, Inc., 1979.

[5] Edwards D., Fleischman G., Marcus B., Theory and design of variable conductance heat pipes: steady state and transient performance, TRW systems Group, Research Report N3, CR - 114530, 107 p., 1972.

[6] Dvirnyi V., Zagar O., et al. Aluminium variable-conductive heat pipes of the communication satellites. Proc. of the International forum "Space technology and application”, Albuquerque, New Mexico, USA, 1999, pp. 949-953, 1999.

[7] Stephan P. Microscale heat and mass transfer phenomena and their influence on macroscopic evaporator performance. Proc. of the $9^{\text {th }}$ Int. Heat Pipe Conf., 1-5 May, Albuquerque, USA, 1995, Vol. 1., pp. 8-17, 1995. 
[8] Romestant C., Alexandre A. Al/NH3 heat pipe model with non uniform heat flux. Proc. of the 10 ${ }^{\text {th }}$ Int. Heat Pipe Conf., 21-25 September, 1997, Stuttgart. Preprints of Session H2, report No. H2-1, pp. 1-5, 1997.

[9] Alexandre A., Girault M., et al. Application of inverse thermal analysis to heat pipes phenomena. Proc. of the $13^{\text {th }}$ Int. Heat Pipe Conf., September, 2004, Shanghai, China Astronautic Publishing House: Beijing, pp. 126-131, 2005.

[10] Lips S., Bonjour J., Lefèvre F. Investigation of evaporation and condensation processes specific to grooved flat heat pipes. Frontiers in Heat Pipes (FHP), 1, 023001, pp. 1-8, 2010.

[11] Smirnov G., Zoy A., Heat exchange at evaporation in capillaries and porous structures. Moscow power institute: Moscow, 440 p., 1999.

[12] Edwards D. Heat and mass transfer in the vicinity of the vapor-gas front in a gas-loaded heat pipe. ASME J. of Heat Transfer. Vol. 94, pp. 155-162, 1972.

[13] Rohani A., Tien C. Steady two-dimensional heat and mass transfer in the vapor-gas region of a gas-loaded heat pipe. ASME J. of Heat Transfer, Vol. 95, No. 3, pp. 377-382, 1973.

[14] Ulamec S. Biele J., et al. Landing on Small Bodies: From the Rosetta Lander to MASCOT and beyond. Acta Astronautica, Vol. 93, pp. 460-466, 2013.

[15] Biering B., Lötzke H.-G., Baturkin V. New approach to the passive thermal control system with low-temperature "AL-NH3" heat pipes: qualification, testing results and flight performance on microsatellite BIRD. Modern science: researches, ideas, results, technologies. Collection of research papers. 2(7), pp. 183-188, 2011.

[16] Baturkin V. Regulative characteristics of thermal control systems on the base of VCHP at variable heat generation and external heat exchange conditions. Proc. of VIII Minsk International Seminar "Heat Pipes, Heat Pumps, Refrigerators, Power Sources”, Minsk, Belarus, pp. 365-371, 2011.

[17] Celotti L., Sołyga M., Baturkin V. et al. MASCOT thermal design - how to deal with late and critical changes. Proc. of the $29^{\text {th }}$ European Space Thermal Analysis Workshop, ESA/ESTEC, Noordwijk, The Netherlands 3-4 November 2015, Appendix F, pp. 123-135, 2015.

[18] Semena M., Gershuni A., Zaripov V. Heat pipes with metal-fibrous capillary structures, [in Russian], Vyshcha shkola, Kyiv, pp. 117-135, 1984.

[19] Ivanovsky M., Sorokin V., Yagodkin I., Physical base of heat pipes [in Russian], Atomizdat, Moscow, pp. 123-158, 1978.

[20] Delil A., van der Vooren J. Uniaxial model for gas-loaded variable conductance heat pipe performance in the inertial flow regime. Proc. of 4 th Int. Heat Pipe Conf., 1981, London, United Kingdom, pp. 359-372, 1981.

[21] Faghri A., Heat pipe science and technology, Taylor \& Francis, pp. 221-266, 1995.

[22] Chi S., Heat pipe theory and practice. A sourcebook, Hemisphere Pub. Corp., pp. 80-92, 1976.

[23] Osipova V., Experimental study of heat exchange, Energia: Moscow, pp. 17$22,1979$. 